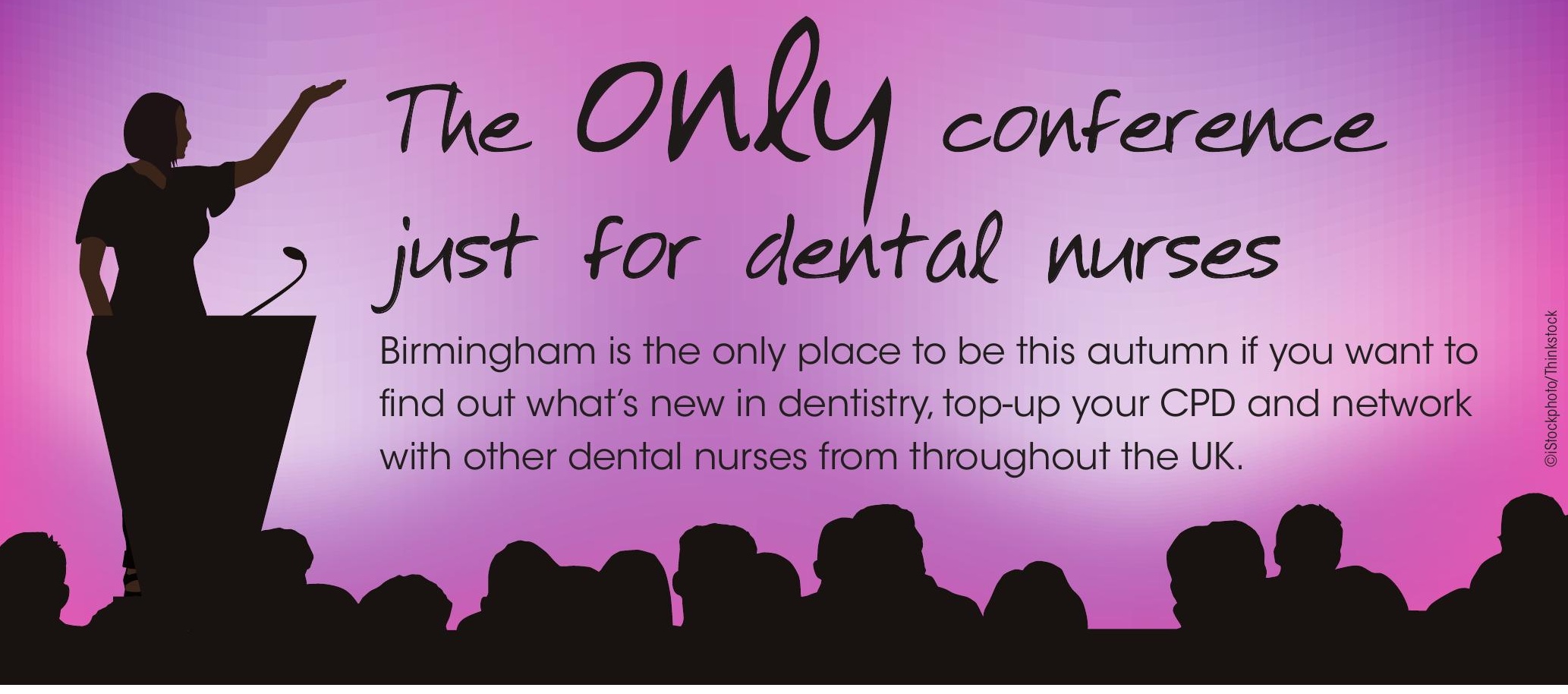

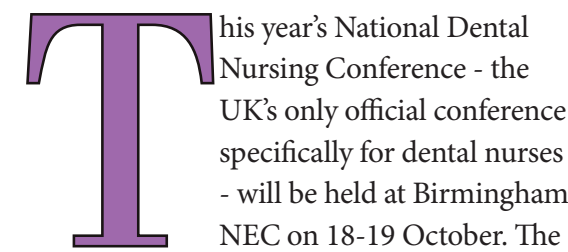

Conference is hosted by the British Association of Dental Nurses (BADN).

The 2013 National Dental Nursing Conference is being held alongside the British Dental Trade Association's (BDTA's) Dental Showcase, to minimise travelling costs for attendees of both events, and has a new format to allow delegates to choose which presentations they want to attend whilst having time to visit Showcase.

\section{Member discount}

Delegates can choose to attend on one or both days of Conference and the registration fee depends on how many days and how many presentations you attend. There is a special discounted rate for current BADN members.

\section{Conference programme}

The conference will begin with an opening ceremony with the inauguration of incoming President Fiona Ellwood and a keynote speech by Dr Nigel Carter of the British Dental Health Foundation.

The presentation programme includes:

- Improving your image - digital photography in the dental practice, by Mike Sharland

- Raising awareness about child trafficking, by Mandy John-Baptiste

- 'Forensic dental identification - it's a jigsaw!?' by Colonel James Hardy

- Tooth whitening - 10 things dental nurses should know, by Diane Rochford

n The role of the Macmillan oral health practitioner, by Emma Riley

- Dental medical emergencies - assessment and treatment, by Peter Whiteford.

The programme offers up to eight hours of verifiable continuing professional development (CPD). There will also be a closing ceremony where the new President will present certificates and acknowledge delegates' achievements over the past year; and the BADN AGM (members only). The conference registration fee includes a buffet lunch and refreshments, conference handbook and verifiable CPD certificate.

\section{Meet the President}

There will be a 'Meet the President' session for new BADN members and first time conference delegates.

\section{Pre-conference dinner}

There will be an informal pre-conference dinner at Jimmy Spices in Solihull - an allyou-can-eat international buffet featuring European, American, Middle Eastern, Far Eastern and Indian dishes. The cost for this is $£ 16.50$ per person which includes service but not drinks which are payable on site. You can reserve your place at the dinner as part of your conference reservation.

\section{Accommodation}

BADN has also reserved a limited number of rooms at the NEC Premier Inn for delegates. Once you have reserved your conference place, you will be sent an email enabling you to reserve a room at the Premier Inn. Or you can choose to stay at one of the many hotels on the Birmingham NEC site - details are available when you register.

\section{Registration}

Registration is online and payment is required at the time of reservation. For more details and to book your place, visit www.badn.org.uk/ conference for the link leading to the online Conference registration site. There you can find information on presentations, speakers, hotels, BDTA Dental Showcase as well as the Frequently Asked Questions page.

\section{BADN membership}

BADN is the UK's only professional association for dental nurses - membership is open to both registered and student dental nurses working in all sectors of dentistry as well as retired dental nurses and other members of the dental team. Full membership (for registered dental nurses) is now available either with $£ 1$ million indemnity cover (from $£ 88.41$ per year - subject to acceptance) or - for those dental nurses who have obtained their cover elsewhere - without indemnity cover ( $£ 50$ per year).

For more information on the National Dental Nursing Conference, go to www.badn.org. uk/conference.

For more information on Full BADN

Membership With Indemnity Cover, go to www.badn.org.uk/sign-up and follow the prompts to join online.

For more information on Full Membership Without Indemnity Cover, or Associate Membership, go to www.badn.org.uk/ sign-up and download the appropriate application form (application for these membership categories is not available online).

For more information on BDTA Dental Showcase visit http://www.dental showcase.com/. 